\title{
Peptic oesophageal stricture: an age-related problem?
}

\author{
N. Gainsborough and P. Powell-Jackson ${ }^{1}$ \\ Clinical Age Research Unit, King's College Hospital, Denmark Hill, Camberwell, London SE5 9RS and \\ ${ }^{1}$ Department of Medicine, Maidstone Hospital, Maidstone, Kent, UK
}

Summary: A one year retrospective study of 76 patients with peptic oesophageal stricture was performed. Analysis of results showed a significant age-related risk of developing peptic oesophageal stricture. Possible age-related risk factors are discussed. Pitfalls in diagnosis and management are highlighted and the role of $\mathrm{H}_{2}$ receptor antagonists, antacids and omeprazole are discussed.

\section{Introduction}

Gastro-oesophageal reflux is the most important cause of oesophageal ulceration. ${ }^{1,2}$ The relationship between gastro-oesophageal reflux and peptic oesophageal stricture (POS) is less well defined. As only a minority of patients with reflux develop POS, other factors therefore must contribute to its development.

There are many factors known to be associated with stricture formation including congenital anomalies, trauma to the oesophagus, postoperative complications, injection sclerotherapy, various medications ${ }^{3-6}$ and reflux oesophagitis and its complications. ${ }^{7,8}$ The elderly may be at particular risk of stricture formation because of alterations in oesophageal motility, increased use of medication, under-reporting of dyspeptic symptoms and possible atypical presentations. In order to study the natural history of POS, we have analysed the medical records of 76 such patients seen in one hospital over a 12 month period and have reviewed its management and possible risk factors.

\section{Methods}

The name of patients were retrieved from endoscopy records for all patients admitted to Maidstone Hospital for dilatation of POS over 12 month period (1.4.88-31.3.89) and cross-checked with Hospital Activity Analysis records which did not identify any additional cases. Patients with diagnoses other than POS (for example, achalasia, carcinoma of the oesophagus) were excluded from the analysis. Where hospital records were inadequate, information was checked with the relevant general practitioner. Details were noted of

Correspondence: N. Gainsborough, M.B., M.R.C.P. Accepted: 18 February 1992 age, current medication, symptoms, endoscopy findings, histology results, management (both endoscopic and pharmacological) and details of dilatations. Incidence figures (per thousand population/year) were calculated using population estimates for the Maidstone Health Authority published by the Office of Population and Census Surveys.

\section{Results}

The study population was divided by age into Groups 1 and 2 (those aged less than 65 years and those over 65 years). The incidence increased almost ten fold in the two groups, from 0.29 per thousand in the under 65 age group (Group 1) to 2.29 per thousand in those over 65 (Group 2) $(P<0.001$, chi-square test) (Table I). There were no statistically significant differences in medication use between the two age groups (Table II).

\section{Symptoms}

Dysphagia was the commonest presenting symptom in both groups, occurring in 60 patients $(79 \%)$ overall, with no significant difference between the groups. It has been present for variable periods, with more elderly patients being symptomatic for a shorter period of time, although this did not reach statistical significance. Dyspeptic symptoms were present in 31 patients overall $(41 \%)$, being more common in Group 1 (7/12 (54\%); not statistically significant). Sixteen patients had no symptoms of dysphagia at presentation, four $(30 \%)$ in Group 1 and $12(19 \%)$ in Group 2. The four patients in Group 1 presented with dyspepsia and in one case vomiting. The patients in the elderly group without dysphagia, presented atypically rather than with dyspepsia, and symptoms included vomiting, 
Table I Age, sex distribution and incidence at diagnosis of peptic oesophageal stricture

\begin{tabular}{lcccc}
\hline & Male & Female & Total & $\begin{array}{c}\text { Cases per } \\
\text { thousand } \\
\text { population/year }\end{array}$ \\
\hline $\begin{array}{l}\text { Group 1 } \\
\text { ( } 565 \text { years) }\end{array}$ & 8 & 5 & 13 & 0.29 \\
$\begin{array}{l}\text { Group 2 } \\
\text { ( }>65 \text { years) }\end{array}$ & 22 & 41 & 63 & 2.29 \\
\hline
\end{tabular}

Table II Medication at time of diagnosis of peptic oesophageal stricture

\begin{tabular}{|c|c|c|c|c|}
\hline & \multicolumn{2}{|c|}{$\begin{array}{l}\text { Group } 1 \\
\leqslant 65 \text { years } \\
(\mathrm{n}=13)\end{array}$} & \multicolumn{2}{|c|}{$\begin{array}{c}\text { Group } 2 \\
\geqslant 65 \text { years } \\
(\mathrm{n}=63)\end{array}$} \\
\hline & No. & $\%$ & No. & $\%$ \\
\hline $\begin{array}{l}\text { Non-steroidal anti- } \\
\text { inflammatory drugs* }\end{array}$ & 1 & 7.7 & 19 & 30.2 \\
\hline Diuretics $\dagger$ & 1 & 7.7 & 15 & 23.8 \\
\hline Slow release potassium & 0 & & 4 & 6.3 \\
\hline Antacids & 3 & 23.1 & 25 & 39.7 \\
\hline $\mathrm{H}_{2}$ receptor antagonists & 4 & 30.8 & 7 & 11.1 \\
\hline Multiple drugs & 7 & 53.8 & 41 & 65.1 \\
\hline
\end{tabular}

* including indomethacin, ibuprofen, diclofenac, fenbufen, naprosyn, piroxicam, ketoprofen; $\dagger$ including potassium-containing preparations: Burinex $\mathrm{K}$ and Navidrex K.

weight loss, haematemesis, atypical chest pain and recurrent pneumonia.

\section{Endoscopic findings}

Strictures were present in the lower one third of the oesophagus in 73 patients $(96 \%)$ with no significant difference between age groups. The three other strictures were present in the mid-third of the oesophagus and in each case associated with reflux oesophagitis. Hiatus hernia was present in 57 patients $(75 \%)$ overall, with no significant difference between age groups. Oesophagitis was present in $40(53 \%)$ with no significant difference between age groups. One patient had Barrett's oesophagus.

Biopsies for histological examination were obtained using flexible endoscopic biopsy forceps. Fifty-nine patients $(78 \%)$ had biopsies taken. In all of them, histology showed chronic inflammatory changes. An additional three patients, who were excluded from the study, were initially thought to have POS but were found on biopsy to have malignancy arising from the oesophagus or cardia.

\section{Treatment}

A total of 424 dilatation procedures were carried out, with a frequency range of 1-6 per year per patient. Complications requiring admission following dilatation procedures consisted of three haematemeses and one perforation; a complication rate of $0.9 \%$. A total of 51 patients were treated with $\mathrm{H}_{2}$ receptor antagonists and antacids, and 40 옹 of these patients $(78 \%)$ required repeat dilatations. Of the 12 patients treated with omeprazole and observed for up to 14 months, only four required repeat dilatations $(33 \%)$.

Fifty-one patients $(67 \%)$ were given antaci together with $\mathrm{H}_{2}$ antagonists. One patient in Group 1 and 11 in Group 2 were treated with omeprazo (16\%). In nine patients, oesophageal strictures had developed whilst receiving $\mathrm{H}_{2}$ receptor antagonist treatment for endoscopically diagnosed hiatus hernia and reflux oesophagitis and in one patient, Barrett's oesophagus. Endoscopies in these patients had been performed 3 months to 4 years prior to the diagnosis of peptic oesophageal stricture. Of these nine patients, five were taking nonsteroidal antiinflammatory drugs (NSAIDs) during this period. Compliance according to the general practitioner and hospital notes was felt to be poor in two of the nine patients.

Four patients underwent fundoplication and repair of hiatus hernia, three because of failed medical treatment after one year and one because of inability to dilate the stricture at initial endoscopy. Two strictures recurred within 6 months.

\section{Discussion}

This study, although limited by small sample size and well-known limitations of retrospective case note studies, highlights certain aspects of POS and age. There have been few recent studies highlighting specific age-related aspects of POS.

The incidence of POS in this study population showed an almost ten fold increase in those over 65 compared to those under 65 . Previous studies have 
shown an increasing frequency of POS in patients over 70 admitted for investigation of hiatus hernia. ${ }^{9}$ In a study of benign oesophageal stricture and the role of NSAIDs, studying consecutive admissions to a dysphagia clinic, the mean age of the stricture group was 74.7 years. ${ }^{5}$ In this study the mean age of patients with benign oesophageal stricture was 75.0 years.

Oesophageal mucosal damage is most commonly caused by gastro-oesophageal reflux and healing by fibrosis may lead to stricture formation. However, stricture formation is not invariable and therefore other factors must play a part. Alteration in oesophageal motility with age may prolong the time taken to clear tablets and refluxate from the oesophagus. ${ }^{8}$ Bonavina et $a l .{ }^{3}$ demonstrated lodgement of radiolabelled capsules taken with $15 \mathrm{ml}$ water, in the oesophagus in 11 of 18 volunteers. When the volume of water chaser used was increased to $120 \mathrm{ml}$, lodgement occurred in only three, all of whom were over 70 years. Oesophageal manometry in 12 healthy volunteers showed that three had a non-specific oesophageal motility disorder - all three were over 70 years, implying a possible age-related change in oesophageal motility. ${ }^{3}$ If oesophageal mucosal damage is one of the precipitants of POS, delayed refluxate clearance and the prolonged presence of tablets within the oesophagus may predispose to oesophageal mucosal damage and therefore to stricture formation in the elderly. ${ }^{5,6}$

Diagnosis of gastrooesophageal reflux and POS in the elderly may be difficult resulting in delays in appropriate investigation and initiation of treatment. From our results, elderly patients more frequently present with symptoms of dysphagia or atypical presentations than dyspepsia. In the Jayawardhana study ${ }^{10}$ of 53 patients aged over 75 with POS presenting for surgery, $89 \%$ of the patients presented with dysphagia, $51 \%$ with weight loss and $12 \%$ with nausea, vomiting, heartburn or gastrointestinal bleeding. This may be related to an increase in $\mathrm{pH}$ of the refluxate in the elderly due to a decrease in acid production with advancing age, ${ }^{8}$ and higher incidence of bile refluxate due to alteration in pyloric sphincter tone. ${ }^{11,12}$ The analgesic effect of NSAIDs may also mask dyspeptic symptoms. Pain perception may be impaired with increasing age resulting in other 'atypical' presentations such as 'silent' myocardial infarction. ${ }^{13}$ There is also a tendency for the elderly population to under-report symptoms and tolerate them longer before seeking medical advice. ${ }^{14}$

Biopsy of oesophageal strictures at the time of endoscopy is important to exclude malignancy, particularly in the elderly. This is highlighted by this study where three strictures, initially thought to be benign, were found on biopsy to be malignant and therefore were excluded from the analysis. Multiple biopsies were performed because of sampling error associated with small endoscopic biopsies.

Several pitfalls of management have been highlighted in this study. Endoscopic dilatation, although a relatively simple procedure with a low complication rate, even among elderly patients, ${ }^{15}$ is insufficient alone as evidenced by the large numbers of repeat dilatations reported in this study. After 6-8 weeks treatment with $\mathrm{H}_{2}$ receptor antagonists, endoscopic healing of oesophagitis occurs in only $20-46 \%$ of patients with erosive oesophagitis. ${ }^{16-18}$ In contrast, effective acid suppression and healing of oesophagitis can now be achieved with omeprazole $^{19-21}$ in more than $80 \%$ of cases, although rapid relapse may occur on stopping treatment. Whether these factors can be extrapolated to progression of POS is not established.

In this study there was an apparent decrease in repeat dilatations with omeprazole treatment compared with $\mathbf{H}_{2}$ receptor antagonists. However, the follow-up period for the omeprazole-treated group was shorter, and with such small numbers no firm conclusion can be drawn.

\section{Acknowledgements}

Dr A.E. Stevens, Mrs L.M. South, Mr P. Jones are acknowledged for allowing us access to their patients records and Dr S.H.D. Jackson for his help with the manuscript.

\section{References}

1. Ismail-Beigi, F., Horton, P.F. \& Pope, L.E. Histological consequences of gastro-oesophageal reflux in man. Gastroenterology 1970, 58: 163-174.

2. Richter, J.E. \& Castell, D.O. Gastro-oesophageal reflux. Ann Int Med 1982, 97: 93-103.

3. Bonavina, L., DeMeester, T.R., McChesney, L., Schwizer, W., Albertucci, M. \& Bailey, R.T. Drug induced oesophageal strictures. Ann Surg 1987, 206: 173-183.

4. Patrick, A.W., Cameron, E.W.J. \& Ford, M.J. Oesophageal stricture following inadvertent ingestion of Steradent tablets in the elderly. Scott Med J 1986, 31: 181.

5. Wilkins, W.E., Ridley, M.G. \& Pozniak, A.L. Benign stricture of the oesophagus: role of NSAID. Gut 1984, 25: 478-480.

6. Heller, S.R., Fellows, I.W., Ogilvie, A.L. \& Atkinson, M. Non-steroidal anti-inflammatory drugs and benign oesophageal stricture. $\mathrm{Br}$ Med J 1982, 285: 167-168.

7. Watson, A. Reflux stricture of the oesophagus. Br J Surg 1987, 74: 443-448.

8. Mold, J.W. \& Rankin, R.A. Symptomatic gastrooesophageal reflux in the elderly. J Am Geriatric Soc 1987, 35: 649-659. 
9. Thompson, H.T. Surgical management of hiatus hernia. NZ Med J 1965, 64: 690-694.

10. Jayawardhana, B.N.M., Knox, J. \& Moghiss, K. Benign oesophageal stricture: The place of surgery in the management of elderly patients. Age Ageing 1990, 19: 31-35.

11. Nano, M., Ferrara, L. \& Camandona, M. Sliding hiatal hernia in elderly: A clinical entity. J Am Geriatr Soc 1981, 29: 463-464.

12. Pellegrini, C.A., DeMeester, T.R., Wernly, J.A., Johnson, L.F. \& Skinner, D.B. Alkaline gastrooesophageal reflux. Am J Surg 1978, 135: 177-184.

13. Pathy, M.S. Clinical presentation of myocardial infarction in the elderly. Br Heart $J$ 1967, 29: 190-192.

14. Bowling, A.P. Contact with general practitioners and differences in health status amongst people over 85 years. $J R$ Coll GP 1989, 39: 52-55.

15. Croker, J.R., Vallon, A.G. \& Cotton, P.B. Benign oesophageal stricture in the elderly - use of cimeditine and fibreoptic dilatation. Age Ageing 1980, 9: 53-58.
16. Wesdorp, E., Bartelsman, J., Pape, K., Dekker, W. \& Tytgat, G.N. Oral cimetidine in reflux oesophagitis: a double blind controlled trial. Gastroenterology 1978, 74: 821-824.

17. Behar, J., Brand, D.L., Brown, F.C. et al. Cimetidine in the 2 treatment of symptomatic gastrooesophageal reflux. Gastro- $\subseteq$ enterology 1978, 74: 441-448.

18. Fiasse, R., Hanin, C., Lepot, A., Descamps, C., Lamy, F. \& $\overrightarrow{\bar{\omega}}$ Dive, C. Controlled trial of cimetidine in reflux oesophagitis. Dig Dis Sci 1980, 25: 750-755.

19. Colin-James, D.G. Acid supression: how much is needed? $B$ Med J 1990, 30: 564-565.

20. Hetzel, D.J., Dent, J., Reed, W.D., et al. Healing and relapse of severe peptic oesophagitis after treatment with omeprazole. Gastroenterology 1988, 95: 903-912.

21. Ruth, M., Enbom, H., Lundell, L., Lonroth, H., Sandberg, $\vec{\circ}$ N. \& Sandmark, S. The effect of omeprazole or ranitidine treatment on 24 hour oesophageal acidity in patients with reflux oesophagitis. Scand J Gastroenterol 1988, 23: $1141-1146$. 